\title{
Study of Biodegradation on Packaging Films Derived from Potato Starch and Maleic Anhydride Grafted LDPE and LDPE Polymer Part-II
}

\author{
Dr. Manjari Sharma ${ }^{1}$ \\ ${ }^{1}$ Department of Applied Sciences, Ambedkar Institute of Advanced Communication Technologies and Research, Geeta Colony, Delhi- \\ 110031
}

\begin{abstract}
Maleated low density polyethylene (with 0.5\% grafted maleic anhydride) \& low density polyethylene have been mixed (1:1) to prepare base material, which has been further mixed with Potato Starch (0-15\%) in single step through commercial grade twin screw extruder and thereafter packaging films have been blown. Samples analyzed through morphology, and Carbonyl Index. The effect of mixing of maleic anhydride grafted LDPE and LDPE (1:1) with 0-15\% starch had shown improvement in mechanical properties of compositions significantly because of the presence of higher percentage of maleic anhydride. Morphological study revealed that degradation in high starch containing samples was high which was confirmed by physical surface examination through SEM. Although Carbonyl Index (CI) measurement is not a direct measurement of degradation but study revealed that there is continuous percentage increase of CI in higher starch containing samples. Which shows that the percentage increase in Carbonyl Index is directly proportional to starch contents in the samples, hence, could also be considered as a direct indicator of degradation.
\end{abstract}

Keywords: LDPE: Low Density Polyethylene; LDPE-g-mA: Low Density Polyethylene-grafted-maleic Anhydride; Biodegradable Polymer; Carbonyl Index, Morphology.

\section{Introduction}

Commercial grade biodegradable polymer product development is the requirement of the day. Simultaneously, there is requirement of a polymer product which undergoes degradation after its useful lifetime. In other words the requirement is to govern the entire life cycle of a system right from its inception till its disposal. The approach is called like 'Cradle to Grave' approach where timings are defined by the human beings. With the approach of mixing Synthetic polymer with natural polymer has gained momentum, but still it has to go large distance. As mixing $30 \%$ Starch is deteriorating properties of TPS blends to a large extent making product polymer difficult to use. Efforts are on with various combinations like mixing TPS with Poly Vinyl Alcohol, with Ploy caprolactone and use of LDPE and HDPE. Still the desired polymeric system is eluding. Prepared products are being analysed starting from raw material acquisition, the production and processing and/or disposal of used items prepared through combinations as well as the routes of disposing.

The present study related the entire process to the point of disposal where in proposed material prepared with an approach of mixing natural and synthetic polymeric is disposed in an environment where degradation of the material takes place in a controlled manner so that it does not harm our environment and is called disposal in Environmentally Sound Manner(ESM). Biodegradation is one of the simplest processes which take place in normal environmental conditions and can be of immense use. It is one of the 12 Principles of Green Chemistry which can be applied through use of natural phenomenon of biodegradation, hence accordingly the present study has been planned. Natural and synthetic polymer are mixed, being polar and non polar components mixing is difficult, hence, starch was chemically treated with glycerol (up to
$30 \%$ ), and low density polyethylene was grafted with $0.5 \%$ maleic anhydride. Grafted LDPE and LDPE mixed 1:1 and then mixed with starch $(0-30 \%)$ [1] called as System-I of which physiochemical characteristics were analysed[2]. Conceptually maleic anhydride present in LDPE shall provide reactive sites for the reaction in between hydroxyl group of starch with anhydride group of LDPE to form ester bond in between polar and non polar components. Thus created system showed improved chemical reactivity in between synthetic and natural polymer immiscible compounds.

Confirmation of chemical reactivity in between maleic anhydride containing low density polyethylene and starch had been done by FTIR:ATR analysis. DSC \& XRD analysis indicated that crystallinity[11-13] decreased linearly with the linear increase in starch contents. XRD had confirmed the increase in crystal size of the system which was attributed to the development of secondary bonds $(\mathrm{H}-$ bonds/Vander wall's forces) between the carbonyl group of LDPE \& hydroxyl group of starch. Thermal stability of the prepared system was not impacted with $30 \%$ starch mix. The maleic anhydride group present in LDPE played a key role in reducing the interfacial energy and thereby promoted interfacial adhesion between starch and LDPE-g-mA. Study of mechanical properties of prepared system showed that tensile strength and percentage elongation had decreased with increase in starch contents. At 5\% starch mixing properties had marginal decrease while at $15 \%$ decrease was significant. Considering practical utility as packaging applications and observations in search of finding optimization level of starch in the composition, system was prepared[3]. Accordingly, starch concentration varied with an interval of $2.5 \%$ to $15 \%$ (called as System-II)[4] to enhance accuracy of system obtaining acceptable levels. 


\section{International Journal of Science and Research (IJSR)}

ISSN (Online): 2319-7064

Index Copernicus Value (2013): 6.14 | Impact Factor (2014): 5.611

These system-II, blown film samples were exposed in compost environment for biodegradation testing. Degraded samples over a span of 12 months were analyzed through
Morphology, and Carbonyl index analysis. The Sample compositions are tabulated in Table 1.

Table 1: Sample Compositions

\begin{tabular}{|c|c|c|c|c|c|}
\hline S. No. (Films) & LDPE composition & Starch composition & S. No. & LDPE composition & Starch composition \\
\hline Sample 1 & LDPE-g-mA + LDPE & $0 \%$ & Sample 5 & LDPE-g-mA + LDPE & $10.0 \%$ \\
\hline Sample 2 & LDPE-g-mA + LDPE & $2.5 \%$ & Sample 6 & LDPE-g-mA + LDPE & $12.5 \%$ \\
\hline Sample 3 & LDPE-g-mA + LDPE & $5.0 \%$ & Sample 7 & LDPE-g-mA + LDPE & $15.0 \%$ \\
\hline Sample 4 & LDPE-g-mA + LDPE & $7.5 \%$ & & & \\
\hline
\end{tabular}

\section{Biodegradation Methodology}

Composting site have been selected at Nursery in Delhi College of Engineering located at latitude $28^{\circ} 45^{\prime} \mathrm{N}$ and longitude $77^{\circ} 07^{\prime} \mathrm{E}$. During sampling, ambient conditions and compost conditions have been monitored. Compost method Eldsater \& Karlsson(1999) [5,6] had been adopted for biodegradability test. Compost had been prepared more than six months before the sampling. The moisture content was maintained by periodic addition of water in the compost. The composting bin was covered by small fragments of green grass. For maintaining aerobic conditions in the composting, network of perforated pipes laid down in the bin and have been pumped with normal air compressor.

\subsection{Constitution of Compost}

The biodegradability tests were performed in a laboratory scale composter and the size of films was $5 \times 5 \mathrm{~cm}$. (5 replicates). The constitution $[7,8,9]$ of solid waste mixture (compost) used for biodegradability testing was as follow: (dry 51 weight): $40.8 \%$ shredded leaves, $11.4 \%$ cow manure/ dung, $15.8 \%$ newspaper and computer paper, $2 \%$ white bread, $7.8 \%$ saw dust, $19.2 \%$ food waste (dry milk, potato, carrot, banana and other vegetables) and 3.0\% urea. Total dry weight was $\sim 5 \mathrm{~kg}$. The moisture content was maintained by periodic addition of water and temperature profile of the compost during testing is shown The composting bin was covered by small fragments of green grass and moisture content was maintained by periodically spraying of water. To avoid anaerobic conditions, the bin was constantly aerated with oxygen through a hollow tube. Composting temperature varied with the temperature of the surrounding atmosphere.

\subsection{Sampling Procedure}

- Sample Size: Films of size $5 \times 5 \mathrm{~cm}$ in 3 replicates have been used.

- Samples placement: The all samples with three replicates placed in approx. $30 \mathrm{~cm}$ distance vertically and horizontally in between samples and such kind of 5 layers were made.

- Samples removal: After composting, samples were removed for testing at defined intervals of 1, 3, 6, 9, 12 Months.

- The samples were washed in the distilled water, dried, wrapped in a clean paper and stored at $25^{\circ} \mathrm{C}$.

\subsection{Evaluation of polymer degradation}

The physical appearance of the blown films surface have been observed by Scanning Electron Microscopy. Surface changes could be analysed through study which had fairly indicated the structural deformation occurred due to starch components at various levels. The carbonyl index study of biodegradable film has been conducted to obtain quantitative information of the structural changes. Although Carbonyl Index is not a direct measurement of biodegradation but it has indirect co-relation which has been exploited. Percentage carbonyl index increase had been calculated and results are plotted.

\subsection{Biodegradation Assessment:}

\section{a) Physical Appearance}

A scanning electron microscope model no. LEO $435 \mathrm{VP}$ has been used to investigate the morphology of the film samples. Each sample have been washed with distilled water and dried in a vacuum oven at $60{ }^{\circ} \mathrm{C}$ for 24 hours. The scanning electron microscope was operated at $15 \mathrm{kV}$. The film surface was sputter coated with gold prior to investigation to avoid surface charging under the electron beam.

\section{b) Carbonyl Index}

Carbonyl group evolution was measured by FTIR (NICOLET Model No.380) of M/s Thermo Scientific. The film samples have been obtained in frequency range of 600 to $4000 \mathrm{~cm}^{-1}$. A carbonyl index (CI) which is defined as the ratio of absorbance (A) at two different wave numbers has been calculated according to equation (1).

$$
\text { Carbonyl Index }=\frac{A_{1779}}{A_{1465}} \ldots \ldots \ldots \ldots \ldots \text {.......equation (1) }
$$

\section{Results and Discussion}

\section{Physical Appearance}

The SEM micrographs for LDPE grafted with maleic anhydride/LDPE (1:1) in various compositions of upto $15 \%$ Starch content, blown films have been shown in Figures 1 to 7. After three months of exposure there was no indication of biodegradation in LDPE film. However, films samples containing $2.5,5,7.5,10,12.5 \& 15 \%$ starch have been obviously degraded as evidenced by existence of small holes on surface of film specially having $15 \%$ starch. The tiny holes have appeared on surface confirming starch removal. This is because there are more sites on film surface that can be attacked by micro-organisms. 


\section{International Journal of Science and Research (IJSR) \\ ISSN (Online): 2319-7064 \\ Index Copernicus Value (2013): 6.14 | Impact Factor (2014): 5.611}

As expected, starch which had chemically reacted with maleic anhydride group of LDPE having more attackable sites on film surface. In first three months, degradation is attributed to microbial attack on starch available on surface of film. Thereafter film surface has been observed to be further deteriorated and may be attributed to breakdown of LDPE backbone which has $0.5 \%$ grafting of polar maleic anhydride. The breakdown may be the result of ester linkages which have been generated by reactivity of chemically treated starch and LDPE backbone containing maleic anhydride. During the study of System-I, it had been observed that the hydroxyl group of starch and anhydride group of LDPE have chemically reacted and generated ester bonds. On quantification of degradation it had been observed that degradation in samples was more than the percentage of starch (as compared to as reported by others as $2 \%$ from $25 \%$ starch mixing $[8,9])$, hence, can be concluded that microbial attack on samples have also damaged the LDPE backbone either by hydrolysis of ester group with available moisture in compost or by oxidation of ester group.

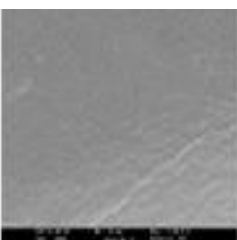

(a)

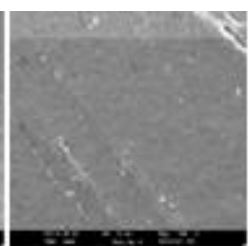

(b)

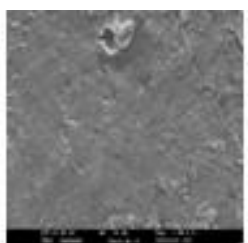

(c)

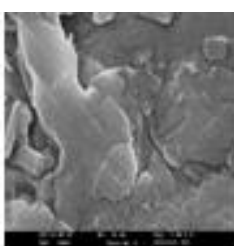

(d)

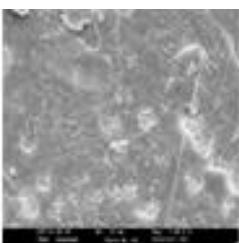

(e)

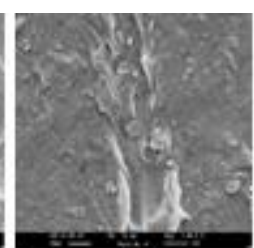

(f)

Figure 1: SEM Sample1(a)0Month (b) 01Month (c) 03Month (d) 06Month (e) 09Month (f) 1 Yr

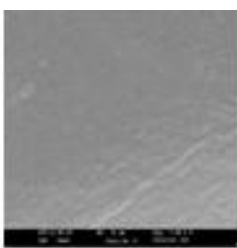

(a)

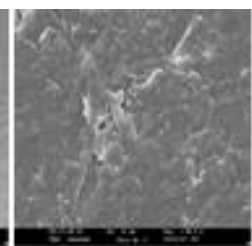

(b)

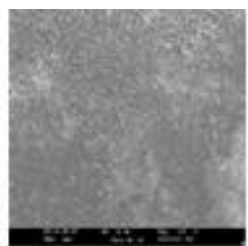

(c)

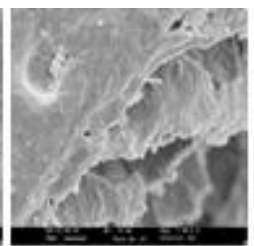

(d)

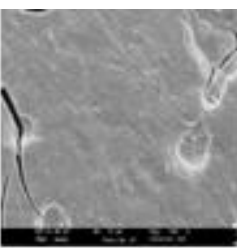

(e)

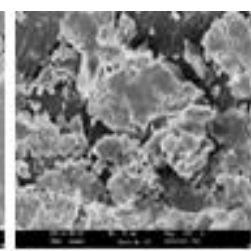

(f)

Figure 2: SEM Sample2(a)0Month (b) 01Month (c) 03Month (d) 06Month (e) 09Month (f) $1 \mathrm{Yr}$

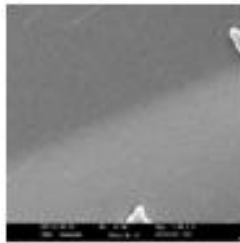

(a)

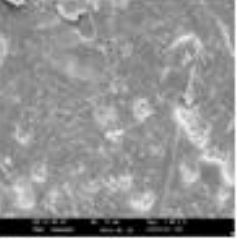

(b)

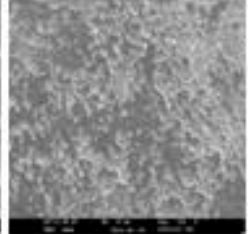

(c)

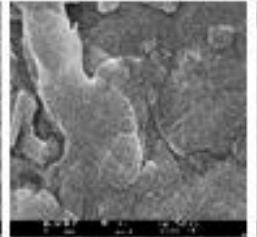

(d)

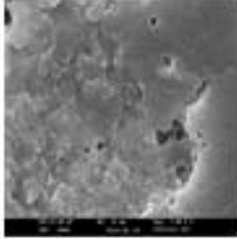

(e)

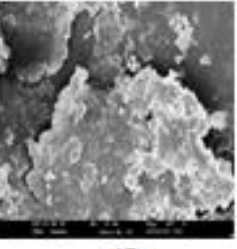

(f)

Figure 3: SEM Sample3(a)0Month (b) 01Month (c) 03Month (d) 06Month (e) 09Month (f) $1 \mathrm{Yr}$

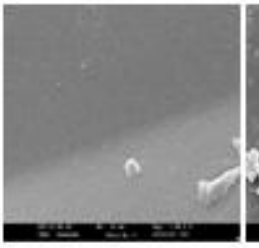

(a)

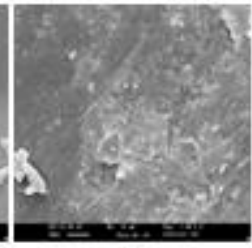

(b)

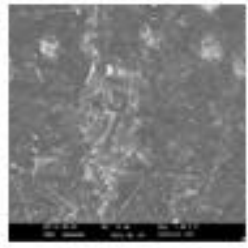

(c)

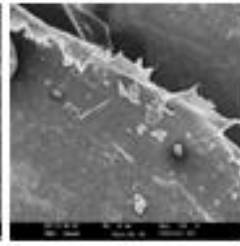

(d)

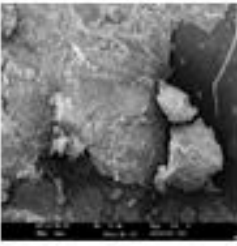

(e)

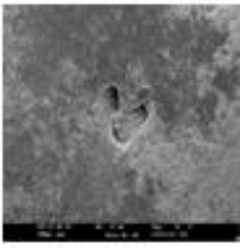

(f)

Figure 4: SEM Sample4(a)0Month (b) 01Month (c) 03Month (d) 06Month (e) 09Month (f) $1 \mathrm{Yr}$

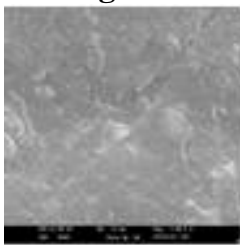

(a)

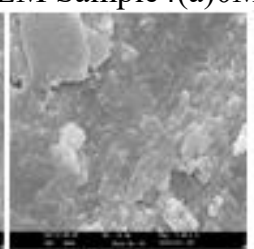

(b)

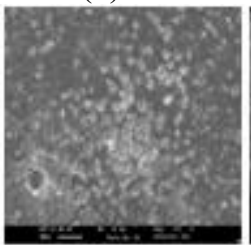

(c)

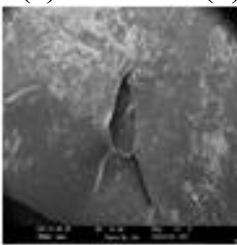

(d)

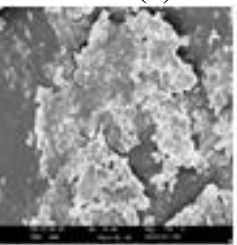

(e)

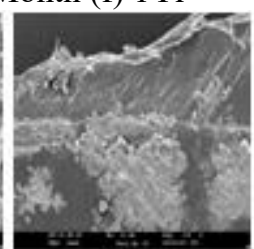

(f)

Figure 5:SEM Sample5(a)0Month (b) 01Month (c) 03Month (d) 06Month (e) 09Month (f) 1Yr 


\section{International Journal of Science and Research (IJSR) \\ ISSN (Online): 2319-7064}

Index Copernicus Value (2013): 6.14 | Impact Factor (2014): 5.611

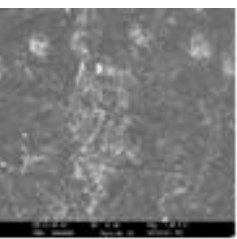

(a)

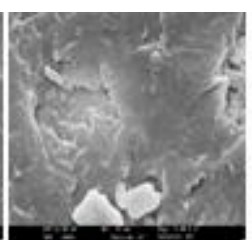

(b)

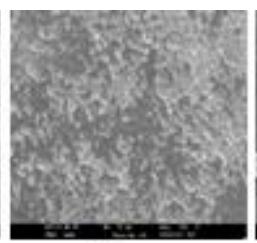

(c)

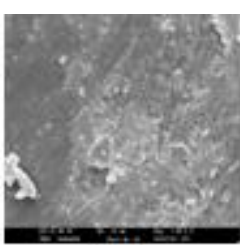

(d)

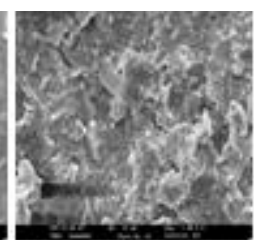

(e)

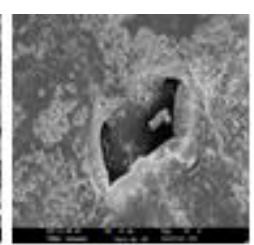

(f)

Figure 6:SEM Sample6(a)0Month (b) 01Month (c) 03Month (d) 06Month (e) 09Month (f) $1 \mathrm{Yr}$

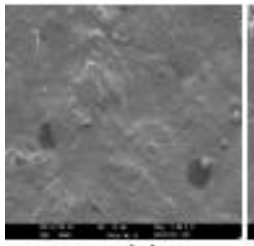

(a)

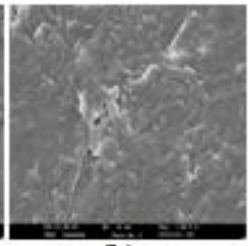

(b)

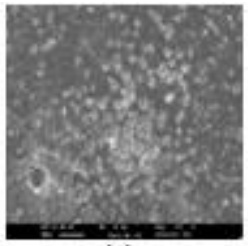

(c)

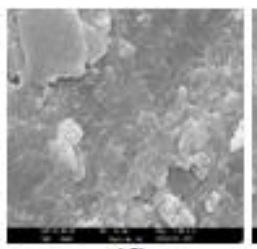

(d)

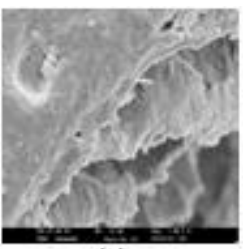

(e)

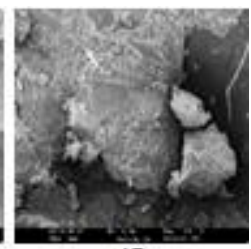

(f)

Figure 7:SEM Sample7(a)0Month (b) 01Month (c) 03Month (d) 06Month (e) 09Month (f) $1 \mathrm{Yr}$

\section{b) Carbonyl Index:}

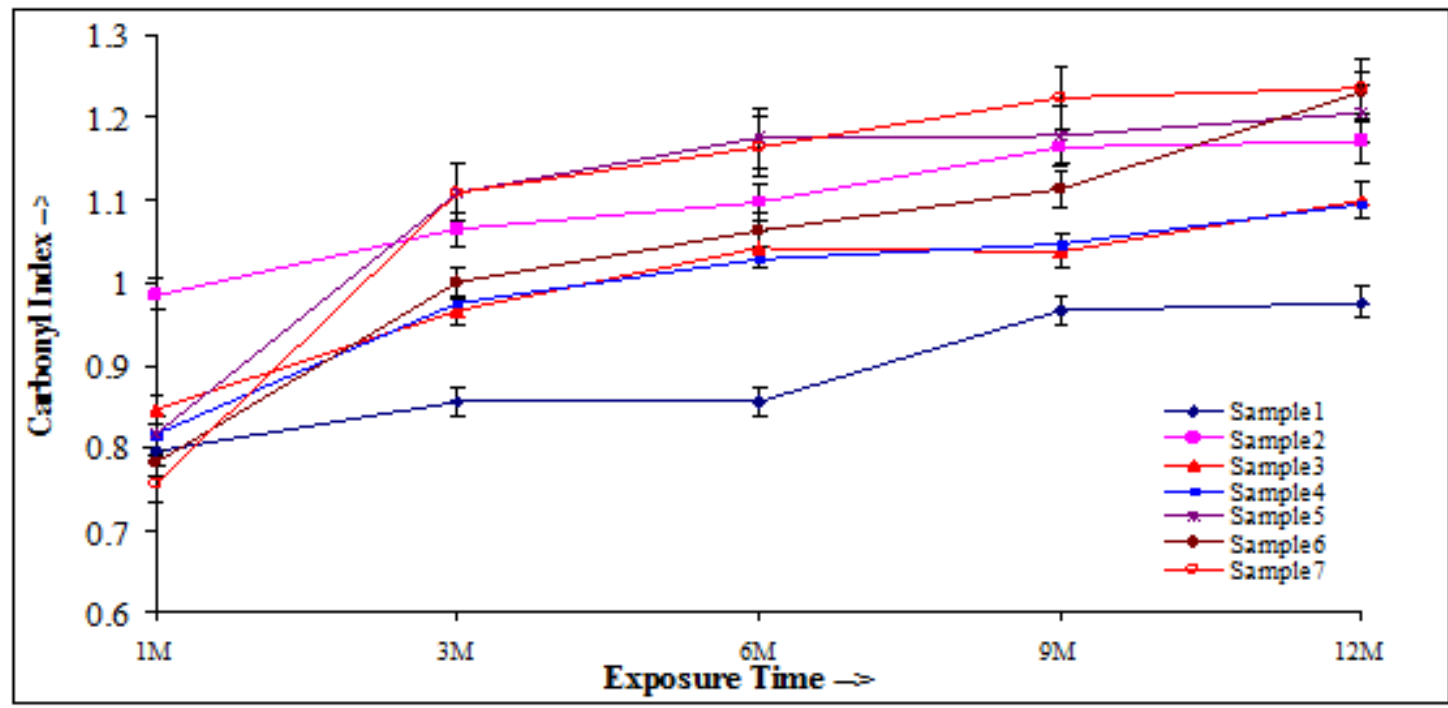

Figure 8: Variation of Carbonyl Index during composting in 15\% Starch content Samples.

Figure 8 shows the variation of the carbonyl index value as a function of exposure time for LDPE/ LDPE-g-MA/ starch sample films. Moderate extent of oxidation of samples is observed which may be attributed to the accumulation of carbonyl functionalities in the polymer. The same was supported through the FTIR analysis[3,4] also. The carbonyl index of LDPE is near to 0.4 which is obvious, because there is no impact of oxidation on pure LDPE.

The LDPE-grafted with maleic anhydride showed quite low value but oxidation does affect the properties and that too, linearly increasing in compost conditions. The highest carbonyl index of 1.235 is observed in the $15 \%$ starch sample, which shows the faster rate of carbonyl build up (specially at high temperature conditions in the compost[10]). The trend is encouraging towards degradation of these samples. Percentage increment in carbonyl index (CI) of LDPE/LDPE grafted maleic anhydride/starch biodegradable polymer films with 12 Months composting study has been shown in figure 9 . 
International Journal of Science and Research (IJSR)

ISSN (Online): 2319-7064

Index Copernicus Value (2013): 6.14 | Impact Factor (2014): 5.611

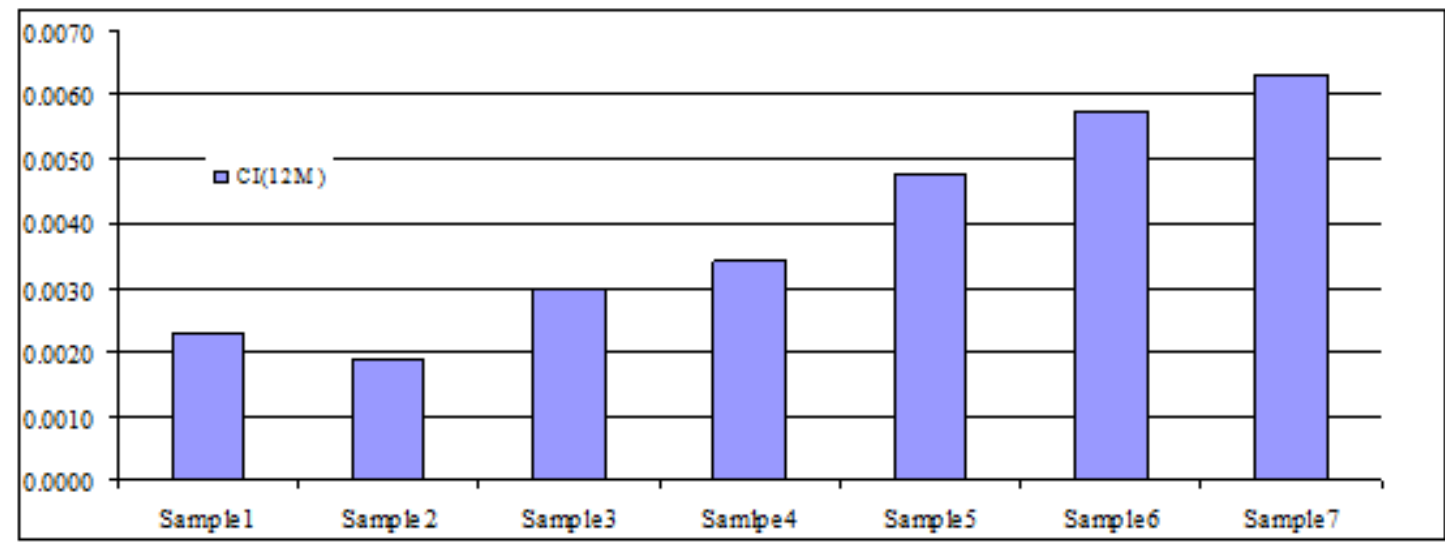

Figure 9: Percentage increment in $\mathrm{CI}$ in polymer films during 12 Months of composting.

\section{Conclusion}

These $15 \%$ starch content based blown film samples were exposed in compost environment for the biodegradation study. The degraded samples over the span of 12 months were analyzed through Morphology analysis through SEM and Carbonyl index analysis. The biodegradation study indicated that the overall percentage increase in Carbonyl Index (CI) has increased consistently with exposure time of films in compost. The study indicates that the introduction of maleic anhydride group in the LDPE, which formed the ester bond with hydroxyl group of starch, has helped in the degradation of film samples. The degradation results indicate that the ester group, as well as starch, both has helped in the degradation of samples. Physical surface analysis and carbonyl index studies have been confirming more and more degradation of samples in the compost.

\section{References}

[1] Gupta A.P., Sharma M., and Kumar V., J. Poly. Plast. Tech. Eng., 47, 953-959(2008).

[2] Gupta A.P., Kumar V., Sharma M., \& Shukla S.K., J. Poly. Plast. Tech. Eng.,48,6, 587-594(2009).

[3] Gupta A.P., Kumar V., Sharma M., J. of Poly. Env.,18, 484-491(2010)

[4] Gupta A.P., Sharma M., Journal of Polymer and Environment, 18, 492-499 (2010).

[5] Eldsater C., Karlsson S., and Albertsson A.C., J. Polym Degrad Stab, 64 (1999), p.177.

[6] Eldsater C., Karlsson S., Albertsson A.C., Polym Degrad Stab, 64; 177-183: 1999.

[7] Pandey J.K., Reddy R.K., Kumar P.A. and Singh R.P. Polym. Degrad. Stab., 88(2); 234-250:2005.

[8] Pranamuda H., J Envir Polym Degrad, 4;1-7:1996.

[9] Goheen S. M. and Wool R. P., J Appl Polym Sci, 42; 2691-2701: 1991.

[10] Ishak M., Taib R, Ishiaku US, Chapter 4, Handbook of Engineering Biopolymer, Stoyko Fakirov Devis Bhattarchryya, Hanser Publication, Munich, 126,137,144-147:2007.

[11] Chandra, R. and Rustogi R., Polym. Degrad Stab, 56;185-202:1997.

[12] Dalev P.G., Patil R.D., Mark J.E., Vassileva E. \& Fakirov S., J Polym.Sci,78;1341-47: 2000.

[13] Valles-Lluch A, Contat-Rodrigo L and Ribes-Greus A, J Appl Polym Sci, 90; 3359-3373:2003.
[14]Ewa Rudnik, Compostable Polymer Materials, Chapter 8, Environmental impact of compostable polymer materials, Elsevier, $192: 2008$. 